\title{
Research on Supply Chain Financial Risks and Preventive Measures in the Era of Big Data
}

\author{
Weiting Sun ${ }^{1, a}$, Puxue Shen ${ }^{2, b, *}$ \\ ${ }^{1}$ Logistics School, Beijing Wuzi University, Beijing, China \\ ${ }^{2}$ Logistics School, Beijing Wuzi University, Beijing, China
}

\begin{abstract}
The emergence of supply chain finance has reduced the financing costs of SMEs. Due to the development of a diversified supply chain financial subject platform, there is a lack of risk control in terms of theory and practice. Big data is generated in Internet applications and combined with information technology to form big data technology. It can provide financial institutions with large-scale data analysis methods and can effectively improve the efficiency and ability of financial institutions to serve supply chain members. However, big data has some problems, such as higher processing cost, lower authenticity, and difficulty in effectively protecting the privacy and security of users. There are many problems with this new development model. This article focuses on the risk problems faced by supply chain finance. It discusses the use of big data technology to effectively solve the supply chain financial risk problems, and gives some measures that can be effectively solved for how to effectively avoid these risk factors. By effectively solving the financial risk problem in the era of big data, it provides guarantee for the benign development of enterprises, and provides a certain reference for researchers engaged in related fields and workers in this field.
\end{abstract}

\section{Introduction}

After the development of Internet technology in recent years, it has become very mature, and the application of Internet has been popularized in the whole society. All kinds of electronic devices can intervene in the Internet. The widespread construction of network infrastructure and the popularization of smart terminal devices have brought convenience to people using the Internet. Handheld terminal devices are now cheap, and ordinary people are basically one or a few people, which is very convenient to access and use the Internet anytime, anywhere. The use of the Internet has expanded rapidly. During the process of accessing the network, a large amount of data information is generated [1]. The scale of these network data continues to expand, making big data and related technologies a typical feature of the era.

Internet technology has been continuously improved in use, and continuous investment of large amounts of money has led to in-depth research on Internet technology. At present, the communication network technology is also constantly making new breakthroughs. After several years of development, 5G communication technology has made great progress and has been gradually commercialized in various countries. The development and progress of these technologies have led to the rapid development of the information economy, and there is an urgent need to reasonably use big data technology for analysis and integration [2]. The current supply chain finance is a complex network without borders, and its transaction structure is more complicated. Facing the development environment of big data, there are many risks in supply chain finance, and it is necessary to use big data technology to manage and control financial risks [3]. In the process of using big data technology to manage supply chain financial risks, there are still some problems that need to be addressed in a targeted manner. With the guarantee of credit injected by core enterprises, the development of supply chain finance has broadened the financing channels of SMEs, and the financing difficulties of SMEs have been effectively alleviated [4].

\section{Big data and related technologies}

There is no unified definition of big data in academia, and there are many different understandings. On the whole, big data is an information asset, which has the characteristics of large capacity, high speed and variability, relatively low cost and requiring innovative forms of processing. The academic community believes that big data is not only huge in size, but also has four typical characteristics. Big data has large data size, many types of data, rapid processing speed, and high overall value, but low value density [5]. With the advancement and widespread application of Internet technology, Internet users are increasing rapidly, and mobile

ae-mail: 17801215470@163.com; *Corresponding author' e-mail: b763641205@qq.com 
terminals can obtain large amounts of data. Network users' sharing, browsing and other activities will generate a lot of data [6]. The data types of big data include relational data types, and semi-structured and unstructured data such as pictures, audio, and video.

Big data technology is a technology to quickly obtain useful information from various data. Big data processing technology has the following contents in supply chain financial risk management [7].

- In supply chain finance, data collection channels are connected with data from core companies, ecommerce platform transaction databases, and other big data.

- In the data environment, the supply chain financial data has a wide range of sources, and ETL can screen large data sets to obtain target data.

- Supply chain financial risk management needs to build a risk management database, which has a huge storage capacity and can store semistructured and unstructured data.

- In supply risk management, data mining is mainly used for risk assessment and prediction.

- In supply chain financial risk management, it is necessary to use charts, pictures, etc. to display complex data to facilitate the understanding and reading of risk managers.

\section{3 supply chain finance}

The development of economic globalization has made every enterprise no longer exist in isolation, and the further development and progress of Internet technology has greatly improved the efficiency of supply chain management. Multiple enterprises in various fields together form a unity of development [8]. The expansion of the supply chain scale has forced the improvement of management efficiency. However, due to the lack of corresponding funding sources, SMEs cannot receive sufficient financial support, and liquidity is very scarce. The development of the supply chain plays a very serious role in restricting [9]. Therefore, scholars and some experts in related fields have intensified their research on how to solve the problem that hinders the smooth development of the supply chain, and regard this problem as a hot issue of key research. After the emergence of supply chain finance, it has brought new sources of funds to SMEs, provided financing services to SMEs, lowered their financing threshold, and effectively alleviated the shortage of funds for such enterprises. After solving the capital problem, such enterprises can carry out normal business operations and promote the normal operation of the entire supply chain [10].

The rapid development of Internet finance has caused a significant impact on traditional finance. Supply chain finance took the lead in the rise from the banking industry. Banks have launched "trade financing", "logistics financing", "supply chain financing" and so on. The essence of these services is roughly the same. Formally, it is relying on the core enterprises of various industries, using the prepayments for procurement in the supply chain link, and it is operating inventory mortgages, and sales of accounts receivable, etc., to realize the financing of upstream and downstream enterprises in the supply chain. When conducting Internet supply chain finance, banks usually choose companies with strong asset reputation and large business scale as customers [11]. Most of the core enterprises that carry out supply chain financial business mainly carry out business in their own supply chain, and rarely carry out supply chain financial business outside their own industry [12].

In the process of innovation and development, it uses modern high-tech technologies such as the Internet and cloud computing to closely integrate the logistics and cash flow of some small and medium-sized enterprises in the upstream and downstream supply chains of core companies, effectively avoiding the risks that individual companies must face. Transform the risk of an individual enterprise into an overall controllable risk. Nuclear supply chain finance can accelerate the flow of funds and reduce the financing constraints of SMEs. It plays an important role in promoting the construction of the entire industry ecological chain. Its business operation mode is shown in Figure 1.

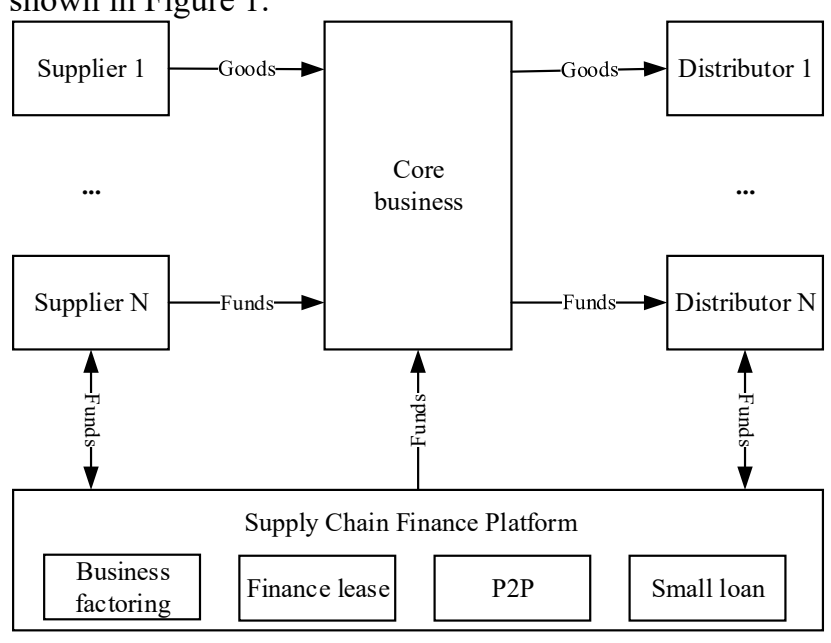

Figure 1. Supply chain financial business operation mode diagram

\section{Supply chain financial risk}

\subsection{Sources of risk in supply chain finance}

Uncertainty is the root cause of risk. The internal and external ecological environment is the uncertainty. Internet technology immaturity and data authenticity are internal uncertainties. It is necessary to face the double risks from the industry chain and finance itself. The industrial chains of different industries are different, and more business processes are involved; Participants in Internet supply chain finance are closely related, and problems at any node may affect the normal and effective operation of the entire supply chain. 


\subsection{Risk categories of supply chain finance}

In the era of big data, the main risks of supply chain finance are mainly reflected in the following aspects.

1) credit risk. In the supply chain finance with enterprises as the core, the operating status and development prospects of the core enterprises have a decisive effect on the survival and development of upstream and downstream enterprises, and will also have an impact on the healthy development of the Internet supply chain financial ecosystem. SMEs are the direct borrowers of supply chain finance. Many SMEs have imperfect management systems, imperfect corporate governance structures, opaque information, and unstable performance. These are potential credit risk factors.

2) Operational risk. If transactions are forged, there will be problems with transaction contracts and accounts receivable, and financial institutions will face huge risks.

3) Liquidity risk. When the liquidity of the Internet supply chain financial system is insufficient, asset value losses and risks are triggered.

\subsection{Supply chain financial risks in the context of big data}

1) The cost of acquiring and processing big data is high:

In actual operation, big data is in a split state, making the above goals difficult to achieve. Because big data is composed of many isolated information, a single platform can only master one-dimensional or severaldimensional data. Risk management needs to introduce more data from the outside, and the decentralized data reduces the risk management effect. Data processing costs are higher. Under normal circumstances, you need to pay for the purchase of data, the system data of different institutions needs to be debugged and docked many times, and building a risk control model based on big data requires a lot of $\mathrm{R} \& \mathrm{D}$ and operation and maintenance costs.

2) It is difficult to guarantee the authenticity of big data. If big data is falsified, big data analysis will make erroneous risk management decisions, resulting in serious consequences. At present, there are many databases in China, but there is a lack of high-quality databases. When applying big data in Internet supply chain finance, data quality is prone to problems. Big data fraud is not easy to be discovered and difficult to supervise. It is easy for others to imitate the behavior of using data fraud to profit, which will cause a credibility crisis.
3) User privacy and security issues. Compared with traditional supply chain finance, replacing traditional risk management with big data is the most prominent feature of Internet supply chain finance. Big data can reduce the operating costs of financial service providers, and consumer privacy is easily violated. Consumers need to provide various personal information to the platform in order to obtain Internet supply chain financial services. There is a sharp contradiction between the protection of personal information and the use by the platform. In order to reduce risks, providers of Internet supply chain financial services will try to grasp customer information as much as possible. Big data restores customer portraits, and also mines a lot of user privacy information. The big data used by Internet supply chain finance mainly includes: all kinds of real information such as user online transaction records and bank account records. These are personal privacy and need to be desensitized before they can be used further. Since the current technology does not classify personal privacy data information, private information is not effectively protected and may be disclosed or extracted at any time.

\section{Supply chain financial risk prevention measures}

\subsection{Build an internal risk control mechanism}

Construct and improve the internal control mechanism, aiming at the financial risk of the Internet supply chain, to achieve early warning, management during the event, and make up after the event. Risk management and control is the core work of supply chain finance [13]. Considering the dual characteristics of Internet and finance possessed by Internet supply chain financial companies, it is necessary to deal with diversified risk issues.

Preventing operational risks is the key work of the internal risk control mechanism. In supply chain finance, the credit link and the internal control model are related to the entire supply chain [14]. It is necessary to integrate the business, financial and transaction data of all enterprises in the supply chain, and the service party will control this information as a whole to achieve the final transaction review. Enterprises need to design internal risk management and control modes in a targeted manner according to their own situation. The design of the internal risk control model of corporate Internet supply chain finance is shown in Figure 2. 


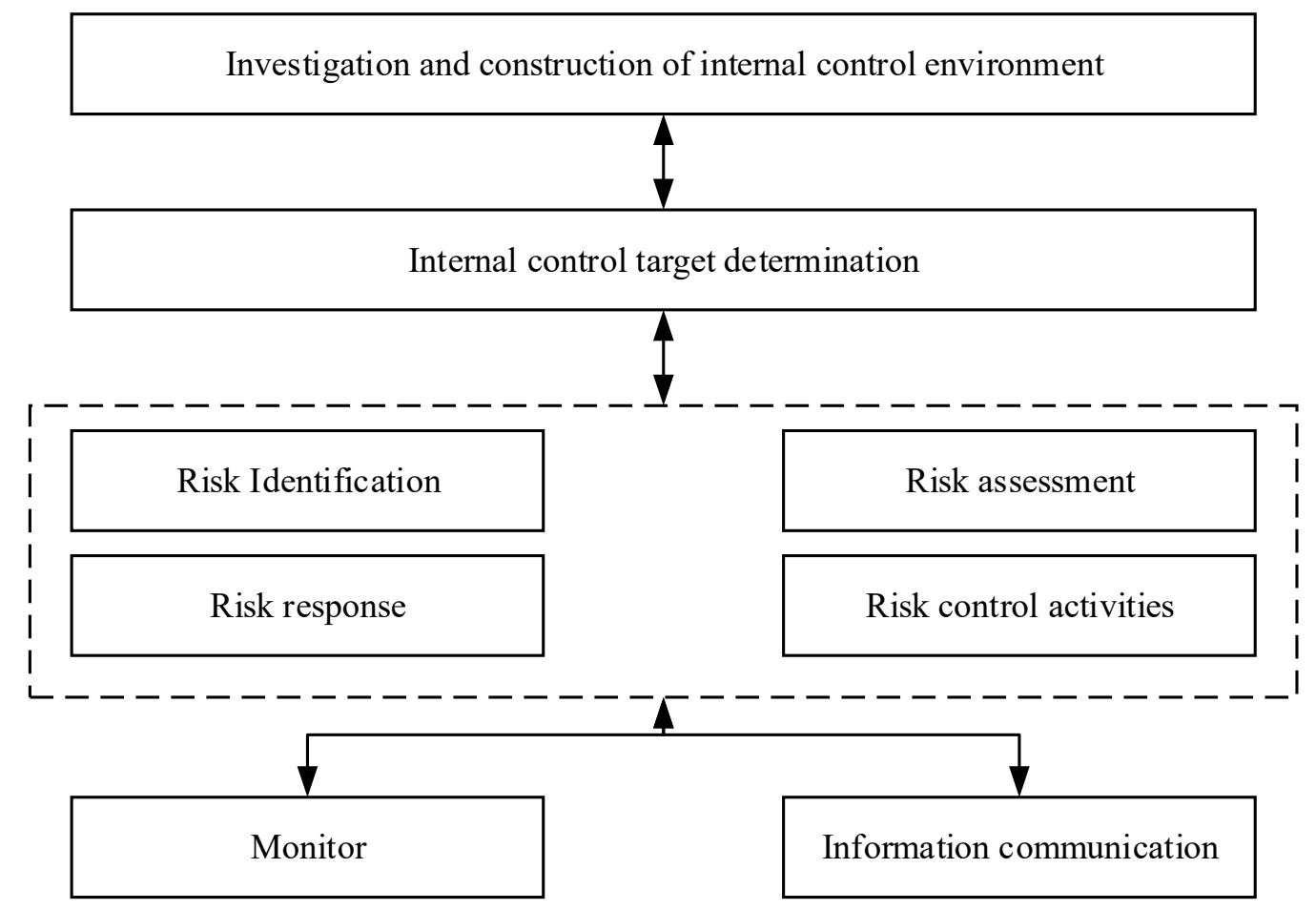

Figure 2. Internal risk control model of Internet supply chain finance

\subsection{Strengthen credit risk control}

Using the multi-dimensional financing application review model and big data technology, with the enterprise as the core, a credit risk evaluation system is constructed, and finally a risk control system is constructed. The core enterprise realizes the supply chain financial risk control of the three links of pre-loan, midloan and post-loan [15]. Core companies use big data technology to complete data collection and analysis, and through modelling, flow control, and quotas, manage and control the risks of various financing nodes to avoid the spread of credit risk.

In the pre-loan link, core companies use big data analysis technology to review user information and complete credit ratings. Core companies can use web crawler technology to mine customers' information on the external Internet to provide help for risk management. The core user supply chain financial user rating process is shown in Figure 3.

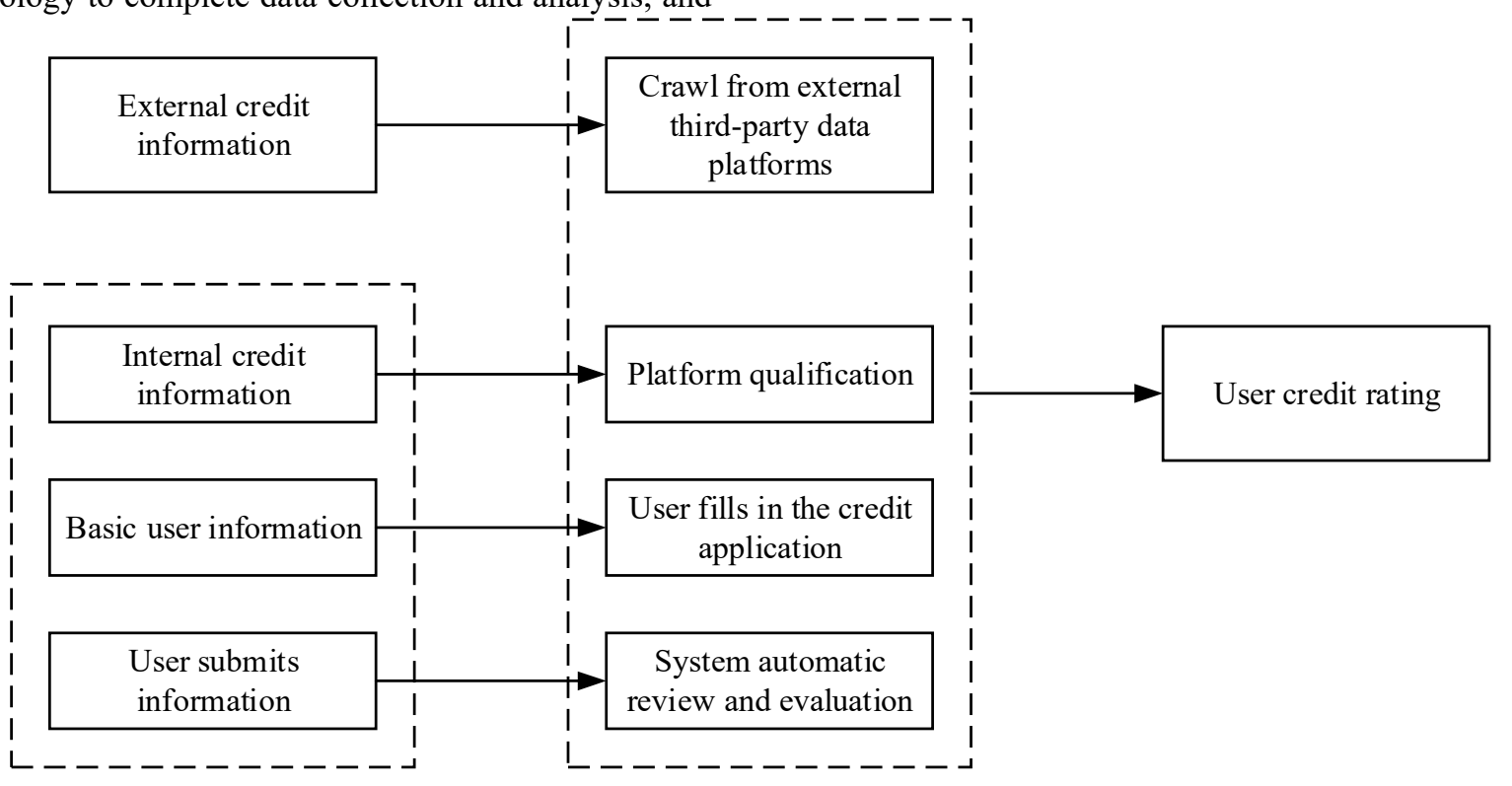

Figure 3. Core user supply chain financial user rating process 


\subsection{Improve risk management model based on big data technology}

Due to the complex external market environment of Internet supply chain finance, on the basis of internal risk management and control and common information technology risk prevention, big data technology is included in the risk identification of Internet supply chain finance. According to the big data technology principles of supply chain finance, machine learning algorithms are used to find the correlation of information from massive data information, combined with big data analysis technology to mine the supply chain financial risks implied by massive data. The design of supply chain financial big data risk control model is shown in Figure 4.

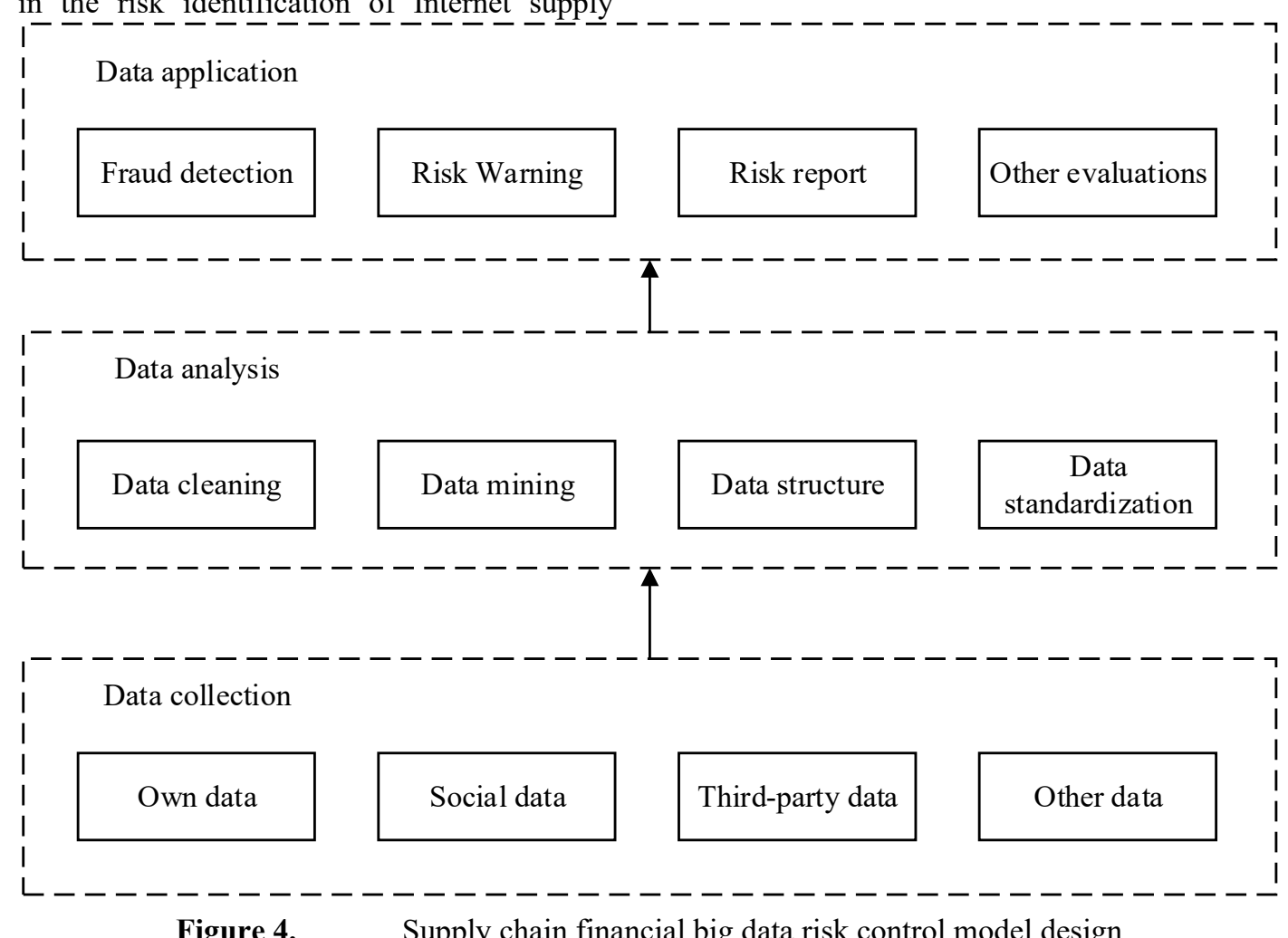

Figure 4.

Supply chain financial big data risk control model design

\subsection{Reduce the cost of acquiring and processing big data}

Strengthen information sharing and improve big data processing capabilities. By strengthening the integration of Internet supply chain finance and social networks, the cost of big data acquisition is reduced. In social networks, there is a large amount of behavior data of financing entities. Service providers of supply chain finance need to strengthen cooperation with Internet companies to promote the breaking of data boundaries and reduce the cost of big data acquisition and processing. Integrate externally collected data, unify data formats and standards, and integrate with internal data.

\subsection{Strengthen the protection of private data}

In the process of big data mining, strengthen the protection of user privacy data. Abide by business rules, abide by national laws on privacy protection, and under this framework, maximize the analytical value of big data. When collecting and storing customer information, it is necessary to obtain the customer 's explicit consent and authorization, and fully disclose the necessary information between the collected information, the purpose of use, the required information and the Internet supply chain financial products to the customer. It is need to further improve big data technology, and to maximize the separation of customer privacy data.

\section{Conclusion}

Supply chain finance lowers the financing threshold for SMEs. During the implementation process, there are many risk factors that have an impact on the stability of supply chain financial business. Therefore, doing a good job in risk management and control is a key task for core companies to develop supply chain financial services. Financial institutions should analyze the root causes of risk problems, classify risk factors, and focus on taking control measures from credit risk, market risk, and operational risk. Big data provides data and technical support to the supply chain financial model and is an important tool for effectively preventing financial risks. In response to some potential security risks arising from the use of big data, necessary precautions should be taken. 


\section{References}

1. J.Y. Liang, C.J. Feng, P. Song, Overview of Big Data Correlation Analysis, Chinese Journal of Computers, 2016, No.1, pp.1-18.

2. Y.K. Wu, H.X. Guo, X.M. Wang, Review of Big Data Technology Research, Journal of Liaoning University (Natural Sciences Edition), 2015, No.3, pp.236-242.

3. G.L. Ji, B. Zhao, A Survey of Spatio-Temporal Data Mining for Big Data, Journal of Nanjing Normal University (Natural Science Edition), 2014, No.1, pp.1-7.

4. L. Wang, X.F. Meng, Review of Research on Privacy Protection of Location Big Data, Journal of Software, 2014, No.4, pp.693-712.

5. F.Z. Fan, G.Q. Su, X.Y. Wang, Research on Credit Risk Evaluation and Risk Management of SMEs under Supply Chain Finance Model, Journal of Central University of Finance \& Economics, 2017, No.12, pp.34-43.

6. M. Pang, M. Hao, Research Review of Supply Chain Finance Risk and Management, Communication of Finance and Accounting, 2017, No.32, pp.45-47+ 129 .

7. P.J. Xu, Wu Shenghan, Research on Innovation and Development of Supply Chain Finance Model Based on "Internet +" Background, Reform of Economic System, 2018, No.5, pp.133-138.

8. J. Feng, C.F. Yuan, Innovation Research on Supply Chain Financial Risk Management under the
Background of Big Data, Business News, 2019, No.33, pp.82-83.

9. Y.H. Tang, W. Duan, Research on the Prevention of Legal Risks in Internet Supply Chain Finance, Journal of Hunan University of Science and Engineering, 2018, No.10, pp.103-104.

10. L. Zhang, Research on blockchain-driven supply chain financial innovation from a game perspective, On Economic Problems, 2019, No.4, pp.48-54.

11. H. Liu, On the status quo of Internet supply chain finance development and risk supervision, Logistics Engineering and Management, 2019, No.9, pp.31-32.

12. J. Li , J.L. Zhang, Research on Credit Risk Identification and Early Warning Model of Supply Chain Finance, Business Management Journal, 2019, No.8, pp.178-196.

13. W. J. Hou, D. Xiang, C. D. Wu, Y. Q. Chen, Internet Supply Chain Financial Risk Evaluation Based on Local Variable Weight Comprehensive Evaluation Method, Journal of Commercial Economics, 2018, No. 24, pp.146-148.

14. $\mathrm{P} . \mathrm{Xu}, \mathrm{Research}$ on Financial Risk Prevention of Agricultural Product Supply Chain Based on Structural Equation Model, Journal of Southwest University of Political Science and Law, 2018, No.6, pp.128-135.

15. M. Tang, L. H. Zhao, Exploration and Practice of Financial Model of Agricultural Supply Chain under Inclusive Finance-Taking Hope Finance as an example, Financial Development Review, 2018, No.11, pp.145-158. 